\title{
Rhetorical Framing and Needle Exchange in Rural Indiana: Shifting Perspectives and Policy
}

\author{
Ryan M. Murphy \\ English, Purdue University, Lafayette, Indiana, United States \\ Objective
}

This abstract proposes a poster presentation aimed at explaining rhetorical framing as a technique for articulating and identifying cases in healtchare policy.

\section{Introduction}

Political discourse surrounding matters of public health is exigent because human life is at stake - this is unquestionably the case with respect to widespread opioid addiction. While intravenous drug use itself is described as a health concern, the spread of diseases such as hepatitis C and HIV through the sharing of needles is a disease surveillance emergency. This research centers on municipal-level decision making in the community of greater Lafayette, Indiana. Here, the mayors of sister cities West Lafayette and Lafayette hold different positions regarding a clean needle exchange program operated by the county health department.

\section{Methods}

As scholars of harm reduction note, "harm reduction disputes are the results of participants placing different weight on moral foundations that drive typical public health discourse" (Alderman et al., 2010). The methodology of rhetorical framing includes vocabulary and tactics for navigating the spaces of different weights and competing values. Articulated by George Lakoff as, "mental structures that shape the way we see the world," framing deliberately selects vocabulary built around a platform of values in order establish the parameters of a discourse (2004). In the case of harm reduction and needle exchange, two different frames compete.

The rule of law and order is a frame that prioritizes civil stability through a fair and unyielding adherence to civil and criminal law. This frame corresponds closely to what Lakoff calls the "strict father" frame which takes a rigid paternalistic approach to responsibility and a binary approach to morality (2004). For the needle exchange program, this frame asserts that the fundamental issue at hand is criminal drug use and that no conciliatory actions should take place to accommodate lawbreaking of any kind.

A different frame can be described as the healthcare and risk reduction frame. This frame seeks to prioritize the healthcare risks associated with drug use and act to abate them. On this view, drug use and addiction is a treatable medical condition. This frame corresponds to what Lakoff calls the "nurturant parent model" (2004). Here nurturance is taken to include responsibility and empathy. In this light, the healthcare frame recognizes the pain and damage caused by drug use for individuals and communities. It holds people responsible by helping them break drug habits rather than simply punish them for being addicted.

This project focuses on a series of radio-broadcast interviews in which the mayor of Lafayette expresses his support of the exchange while the mayor of West Lafayette voices his concerns. I argue the reason for the difference in opinion, despite both mayors agreeing on the essential facts, rests on the problem of invoking conflicting frames. On one hand, the healthcare and risk reduction frame sees the needle exchange as a form of harm reduction and something that generally improves public health. At the same time, the frame of rule of law and order interprets the needle exchange as a government complicity in illegal drug use.

\section{Results}

Rhetorical framing in health communication is a strategy for effectively reaching expert and non-expert audiences alike. Rhetorically framing disease communication achieves two key functions: it identifies a specific focus and it usually minimizes situational features that are outside of the focus. In this case study, both mayors previously had careers as police officers in the local police department. One mayor adheres to the rule of law and order frame to maintain ties with his colleagues in law enforcement while the other is willing to split and adopt the healthcare and risk reduction frame. This commonality permits another remarkable discussion - what does it take to persuade someone to adopt a different frame? 
Beyond shaping policy opinion toward the needle exchange and disease prevention, rhetorical framing establishes the types of surveillance and data that policy makers consider meaningful in terms of measuring success. Whereas the healthcare risk and reduction frame is willing to consider qualitative reports of opioid users who visit the exchange and seek further treatment, the rule of law and order frame is inclined to insist on quantitative data such as the rate of return for needles exchanged or reductions in drug use or the spread of hepatitis $\mathrm{C}$ and other diseases transmitted through the use of shared needles. In addition to differences in data types, rhetorical framing also helps to explain differences in methodological approach to data collection and surveillance.

\section{Conclusions}

In this case, political support by the mayors depends on which interpretive frame takes precedence and the rhetorical delivery and framing of available data often determines which frame dominates. Whereas some data (anecdotal evidence) can be modulated and delivered through appropriate framing, other types of data (the rates of return for needles) cannot be so easily reframed. At minimum, rhetorical framing is capable of determining whether public policy concerning needle exchange is communicated primarily as a public health issue or as a matter of criminal law. For disease surveillance more broadly, rhetorical framing provides not only specialized vocabularies for describing observations, but also helps to identify research perspectives including points of overemphasis and potential blindness.

\section{Acknowledgement}

I would like to acknowledge Professor Richard Johnson-Sheehan and the interview staff at WBAA for making this project possible.

\section{References}

Alderman J, Dollar KM, Kozlowski LT. 2010. Commentary: Understanding the Origins of Anger, Contempt, and Disgust in Public Health Policy Disputes: Applying Moral Psychology to Harm Reduction Debates. J Public Health Policy. 31(1), 116. PubMed https://doi.org/10.1057/jphp.2009.52

Dennis, John “Ask the Mayor: West Lafayette's John Dennis on Leading a Disposable City.” Ask the Mayor, by Stan Jastrzebski, 2 November 2017.

Dennis, John “Ask the Mayor: West Lafayette's John Dennis on Paths (Walking, Driving and to Recovery).” Ask the Mayor, by Stan Jastrzebski, 13 December 2017.

Harm Reduction International. Global State of Harm Reduction 2016, https://www.hri.global/files/2016/11/14/GSHR2016_14nov.pdf. Accessed 15 February 2018. Lakoff, George, Don't Think of an Elephant: Know Your Values and Frame the Debate. Chelsea Green, 2004.

Paul, Joseph. "Needle exchange to open its doors Friday near downtown Lafayette.” Journal \& Courier. 9 August 2017. Updated 2:50 p.m. ET.

Roswarski, Tony “Ask the Mayor: Lafayette's Tony Roswarski on Affordable Housing and Needle Numbers.” Ask the Mayor, by Stan Jastrzebski, 14 December 2017.

Roswarski, Tony “Ask the Mayor: Lafayette's Tony Roswarski on Crossings, Water Bills and Softball Numbers.” Ask the Mayor, by Stan Jastrzebski, 18 September 2017

ISDS Annual Conference Proceedings 2019. This is an Open Access article distributed under the terms of the Creative Commons AttributionNoncommercial 4.0 Unported License (http://creativecommons.org/licenses/by-nc/3.0/), permitting all non-commercial use, distribution, and reproduction in any medium, provided the original work is properly cited. 